\title{
On school violence in Korean middle school, prevention and reaction measures
}

\author{
Se-Jeong Kwon' ${ }^{1}$ Tae-Young Kim ${ }^{2, *}$ \\ ${ }^{1}$ College of Sport Science, Chung-Ang University, Anseong, Korea \\ ${ }^{2}$ College of Education, Hankuk University of Foreign Studies, Seoul, Korea
}

This study is aiming to explore the practical and realistic measure in more variable way, which enables us to manage the problems about school violence we are currently facing as well as to overcome limitations in the current situation where we react only with punishments, mainly in the form of the law enforcement, supported by the police. This study was conducted on male and female students $(n=424)$ and teachers $(n=136)$ attending at the seven middle schools located in Seoul. The frequency analysis, one way ANOVA F-test, t-test, the multiple regression analysis were applied. Students recognize' harmful environmental cleanup' as an important variable or factor to reduce school violence.
Also, both teachers and students are aware that 'regular survey on school violence' could reduce school violence. In conclusion, it is considered that as an effective and viable prevention measure against school violence, more attention and affection efforts need to be activated and addressed, on the part of home, school, and government, which will enable our young generations of students to be brought up, and take up the future of our country.

Keywords: Korea, School violence, Prevention, Consideration, Attention

\section{INTRODUCTION}

School violence, which is becoming a controversial issue relating to education in today's societies, has displayed changes in the patterns and severity of group or organized violence, with a shift towards younger ages and more diverse patterns of violence, including the emergence of harassment with force as a new pattern; therefore, strengthening fundamental humanity education is considered a very urgent issue. This phenomenon has emerged due to the interactions of the uniform entrance-exam-oriented education, ignoring holistic education, and the factors affecting school violence, such as the nuclearization of family, the adverse effects of the mass media, and harmful facilities, which have caused school violence to become a serious social problem. Furthermore, school violence has broadened in scope, from higher grades to lower grades and from boys to girls, above all, with the features that most of the victims tolerate the painful and abusive situations out of fear of reprisals from the offenders, or of criticism and the 'bullying' of friends for ratting on peers (Siegel et al., 1989). In addition, with the atmosphere in which teachers don't want the occurrence of school violence to become known outside due to the burden of damaging the school honor and facing accountability, the invisibility of school violence is becoming increasingly intensified, allowing a vicious cycle to be created (Zillmann, 1988). As a result, the parents of the victims suffer mentally from the violence, while the victimized students sometimes refuse to attend school or run away from home, which leads to the litigations, which stresses the importance of making collaborative efforts, as well as the urgent requirement of the attention of the entire society, including homes, schools and communities (Conklin, 1992).

As for the recently occurring school violence, considering that the offenders do not even recognize what they are really doing wrong, the violence has become an act of ignoring the importance of human dignity and life. It can be said that the violence has developed into crime beyond the level of misconduct that is likely to temporarily be performed during the school days, making it is a serious
${ }^{*}$ Corresponding author: Tae-Young Kim

College of Education, Hankuk University of Foreign Studies, 107 Imun-ro, Dongdaemun-gu, Seoul 130-791, Korea

Tel: +82-2-2173-2202, Fax: +82-2-2173-3934, E-mail: ktyoung66@hanmail.net

Received: January 31, 2015 / Accepted: February 22, 2015
This is an Open Access article distributed under the terms of the Creative Commons Attribution Non-Commercial License (http://creativecommons.org/licenses/by-nc/3.0/) which permits unrestricted non-commercial use, distribution, and reproduction in any medium, provided the original work is properly cited. 
social problem. Although the police are conducting diverse operations and activities such as the honor-police boy scouts, the child-safety guardian house, the school-road-safety patrol, the one-to-one guidance of problem students, and the crime-prevention classroom in an effort to eradicate school violence, there are limitations in the prevention efforts due to the increasing seriousness and broadening scope of the violence occurring. From the results of a survey conducted by the Youth Violence Prevention Foundation on 4,073 students of 64 schools in Korea, including elementary schools, middle schools and high schools, $22 \%$ of the students responded that they had been victims of violence, while $16 \%$ of these students responded that they suffered from deadly pain, which indicates that school violence is not a problem that can be passed off as 'the simple fights between children', but is a problem requiring urgent prevention education on the level of entire schools. In this context, this study will attempt to identify the practical and realistic measures which can be taken against school violence by examining how the students perceive the real situation of school violence, the attitudes with which they see it, and the violence-prevention status and measures taken on the part of the students and teachers while overcoming the limitations in the current situation wherein we react only with punishment from the police in accordance with the law.

\section{MATERIALS AND METHODS}

\section{Data collection}

Male and female students and teachers from 7 middle schools were selected as the sample population for this study. The survey period was from November 27, 2012, to December 21, 2012, during which time data were collected using a structured questionnaire. The socio-demographic characteristics of the teachers and students used in this study are shown in Table 1.

\section{Measurement}

The questionnaire consisted of questions regarding general information, status of school violence, school violence awareness, and school violence prevention and eradication.

\section{Analysis method}

The collection rate of the questionnaire was $97 \%$ for the teachers (146 copies collected out of 150 distributed), while the rate was $96 \%$ for the students ( 424 copies collected out of 440 distributed). Therefore, the surveys from 570 participants were used in the final analysis. For statistical analysis, the frequency analysis, $F$-test and t-test by one way ANOVA, and multiple regression analysis were
Table 1. Socio-demographic characteristics of teachers and students

\begin{tabular}{|c|c|c|c|c|}
\hline Variables & Classification & $\begin{array}{l}\text { Teachers } \\
(n, \%)\end{array}$ & $\begin{array}{l}\text { Students } \\
(\mathrm{n}, \%)\end{array}$ & $\begin{array}{l}\text { Total } \\
(n, \%)\end{array}$ \\
\hline \multirow[t]{2}{*}{ Sex } & Male & $29(19.9)$ & 207(48.8) & $236(49.1)$ \\
\hline & Female & $117(80.1)$ & $217(51.2)$ & $334(50.8)$ \\
\hline \multirow{3}{*}{$\begin{array}{l}\text { Male/female school distinction } \\
\text { for students and teachers }\end{array}$} & Male school & $3(2.1)$ & $6(1.4)$ & $9(1.5)$ \\
\hline & Female school & $38(26.0)$ & $70(16.5)$ & $108(18.9)$ \\
\hline & Coed school & $105(71.9)$ & $348(82.1)$ & $453(79.4)$ \\
\hline \multirow[t]{4}{*}{ Age } & $20 \mathrm{~s}$ & $22(15.1)$ & - & $22(15.1)$ \\
\hline & $30 \mathrm{~s}$ & $51(34.9)$ & & $51(34.9)$ \\
\hline & $40 \mathrm{~s}$ & $59(40.4)$ & & $59(40.4)$ \\
\hline & $50 \mathrm{~s}$ & $14(9.6)$ & & $14(9.6)$ \\
\hline \multirow[t]{3}{*}{ Grades } & First grade & - & $62(14.6)$ & $62(14.6)$ \\
\hline & Second grade & & $242(57.1)$ & $242(57.1)$ \\
\hline & Third grade & & $120(28.3)$ & $120(28.3)$ \\
\hline \multirow[t]{3}{*}{ Home education } & Good & - & $76(17.9)$ & $76(17.9)$ \\
\hline & Middle & & $313(73.8)$ & $313(73.8)$ \\
\hline & $\mathrm{Bad}$ & & $35(8.2)$ & $35(8.2)$ \\
\hline \multirow[t]{4}{*}{ Years of work as teacher } & $0-9 \mathrm{yr}$ & $59(40.5)$ & - & $59(40.5)$ \\
\hline & $10-19 y r$ & $38(26.2)$ & & $38(26.2)$ \\
\hline & $20-29 \mathrm{yr}$ & $43(29.5)$ & & $43(29.5)$ \\
\hline & Over $30 \mathrm{yr}$ & $6(4.1)$ & & $6(4.1)$ \\
\hline
\end{tabular}

performed using the SPSS WIN 18.0 program.

\section{RESULTS}

\section{Perceptions of students and teachers about the status of} school violence

The school violence status was examined in terms of the following: whether or not the subject had experience with the victims of violence, the frequency of the violence, changes in the state of mind of the victims, attitude of the offending students, the time at which the violence occurred, the type of offenders, the place at which the violence took place, and the presence or absence of a group perpetrating the violence. The results of examining the school violence status as perceived by the students and teachers are presented in Table 2 .

\section{The consciousness status of the students and teachers about school violence}

The consciousness status of the survey subjects about school violence was identified by examining what the subjects think about the following question items: the extent of the school violence, the types of violence, the reasons for the violence, the characteristics of the offenders, people the students ask for help from, the reason some students do not ask for help, the level of the help obtained when asking for help, and the institutions which should 
Table 2. Perceptions of students and teachers about the status of school violence

\begin{tabular}{|c|c|c|c|c|c|}
\hline \multirow{2}{*}{ Variables } & \multirow{2}{*}{ Classification } & \multirow{2}{*}{ Teacher (n, \%) } & \multicolumn{3}{|c|}{ Students (n, \%) } \\
\hline & & & Total & Male & Female \\
\hline \multirow[t]{6}{*}{ Experience with the victims of violence } & 1-3 times & $36(25.0)$ & $123(29.0)$ & $69(33.3)$ & $54(24.9)$ \\
\hline & 4-6 times & $34(23.6)$ & $50(11.8)$ & $32(15.5)$ & $18(8.3)$ \\
\hline & 7-9 times & $13(9.0)$ & $21(5.0)$ & $13(6.3)$ & $8(3.7)$ \\
\hline & 10-12 times & $13(9.0)$ & $3(0.7)$ & $2(1.0)$ & $1(0.5)$ \\
\hline & Over 13-15 times & $34(23.6)$ & $18(4.2)$ & $14(6.8)$ & $4(1.8)$ \\
\hline & None & $14(9.7)$ & $209(49.3)$ & $77(37.2)$ & $132(60.8)$ \\
\hline \multirow[t]{6}{*}{ Frequency of the violence } & $1-2$ times a week & $21(14.8)$ & $119(28.1)$ & 71 (34.3) & $48(22.2)$ \\
\hline & $1-2$ times a month & $50(35.2)$ & $139(32.9)$ & 73 (35.3) & $66(30.6)$ \\
\hline & $1-2$ times per 6 month & $25(17.6)$ & $46(10.9)$ & $21(10.1)$ & $25(11.6)$ \\
\hline & 1-2 times a year & $35(24.6)$ & $34(8.0)$ & $10(4.8)$ & $24(11.1)$ \\
\hline & 1-2 times every two years & $6(4.2)$ & $12(2.8)$ & $7(3.4)$ & $5(2.3)$ \\
\hline & None & $5(3.5)$ & $73(17.3)$ & $25(12.1)$ & $48(22.2)$ \\
\hline \multirow[t]{6}{*}{ Changes in the state of mind of the victim student } & Dislike going to school & $107(75.4)$ & $225(54.1)$ & $89(43.2)$ & $48(22.2)$ \\
\hline & Want to be transferred to another school & $17(12.0)$ & $48(11.5)$ & $73(35.3)$ & $66(30.6)$ \\
\hline & Want to run away from home & - & $8(1.9)$ & $21(10.1)$ & $25(11.6)$ \\
\hline & Want to revenge & $6(4.2)$ & $74(17.8)$ & $10(4.8)$ & $24(11.1)$ \\
\hline & Don't care & $2(1.4)$ & $37(8.9)$ & $7(3.4)$ & $5(2.3)$ \\
\hline & Other & $10(7.0)$ & $24(5.8)$ & $25(12.1)$ & $48(22.2)$ \\
\hline \multirow[t]{6}{*}{ The attitude of the offender students } & Regretted and stopped the violence & $22(15.8)$ & $31(7.6)$ & $14(6.9)$ & $17(8.3)$ \\
\hline & Regretted but continued to join in the violence & $39(28.1)$ & $68(16.7)$ & $37(18.2)$ & $31(15.1)$ \\
\hline & Justified the violence and continued to participate & $7(5.0)$ & $69(16.9)$ & $36(17.7)$ & $33(16.1)$ \\
\hline & Justified the violence but stopped participating & $12(8.6)$ & $32(7.8)$ & $14(6.9)$ & $18(8.8)$ \\
\hline & Continued the violence without thinking. & $53(38.1)$ & $196(48.0)$ & $98(48.3)$ & $98(47.8)$ \\
\hline & Other & $6(4.3)$ & $12(2.9)$ & $4(2.0)$ & $8(3.9)$ \\
\hline \multirow[t]{7}{*}{ Time at which the violence occurred } & On the way to school & - & $2(0.5)$ & - & $2(1.0)$ \\
\hline & During school & $30(20.7)$ & $73(17.6)$ & $38(18.6)$ & $35(16.7)$ \\
\hline & During rest hours & $19(13.1)$ & $131(31.6)$ & $100(49.0)$ & $31(14.8)$ \\
\hline & During lunch hour & $4(2.8)$ & $30(7.2)$ & $13(6.4)$ & $17(8.1)$ \\
\hline & On the way home & $23(15.9)$ & $36(8.7)$ & $11(5.4)$ & $25(11.9)$ \\
\hline & After school & $52(35.9)$ & $120(29.0)$ & $33(16.2)$ & $87(41.4)$ \\
\hline & Other & $17(11.7)$ & $22(5.3)$ & $9(4.4)$ & $13(6.2)$ \\
\hline \multirow[t]{5}{*}{ Type of offender } & A lone student & $21(14.6)$ & $76(18.4)$ & $53(26.0)$ & $23(11.0)$ \\
\hline & 2-3 students & $53(36.8)$ & $114(27.6)$ & 72 (35.3) & $42(20.1)$ \\
\hline & $4-5$ students & $46(31.9)$ & $92(22.3)$ & $35(17.2)$ & $57(27.3)$ \\
\hline & Over 5 or a group & $23(16.0)$ & $124(30.0)$ & $40(19.6)$ & $84(40.2)$ \\
\hline & Others & $1(0.7)$ & $7(1.7)$ & $4(2.0)$ & $3(1.4)$ \\
\hline \multirow[t]{8}{*}{ Violence place } & Inside of the school & $24(16.6)$ & $141(33.9)$ & $98(47.8)$ & $43(20.4)$ \\
\hline & On the way home after school & $32(22.1)$ & $97(23.3)$ & $45(22.0)$ & $52(24.6)$ \\
\hline & Nearby private study centers & $8(5.5)$ & $30(7.2)$ & $12(5.9)$ & $18(8.5)$ \\
\hline & Game room, PC room & $18(12.4)$ & $54(13.0)$ & $18(8.8)$ & $36(17.1)$ \\
\hline & Playgrounds, parks & $36(24.8)$ & $54(13.0)$ & $24(11.7)$ & $30(14.2)$ \\
\hline & Karaoke & $1(0.7)$ & $7(1.7)$ & - & $7(3.3)$ \\
\hline & Friend's house, rented rooms & - & $2(0.5)$ & $1(0.5)$ & $1(0.5)$ \\
\hline & Other & $26(17.9)$ & $31(7.5)$ & $7(3.4)$ & $24(11.4)$ \\
\hline \multirow[t]{2}{*}{ Group participation in the violence } & Yes & $2(1.4)$ & $21(5.2)$ & $11(5.7)$ & $10(4.8)$ \\
\hline & No & $141(98.6)$ & $380(94.8)$ & $182(94.3)$ & 198 (95.2) \\
\hline
\end{tabular}


Table 3. The consciousness status of the students and teachers on the school violence

\begin{tabular}{|c|c|c|c|c|c|}
\hline \multirow{2}{*}{ Variables } & \multirow{2}{*}{ Classification } & \multirow{2}{*}{ Teacher (n, \%) } & \multicolumn{3}{|c|}{ Students (n, \%) } \\
\hline & & & Total & Male & Female \\
\hline \multirow[t]{6}{*}{ The extent of violence } & Very serious & $15(10.3)$ & $47(11.1)$ & $21(10.2)$ & $26(12.0)$ \\
\hline & Rather serious & $68(46.9)$ & $128(30.3)$ & $54(26.2)$ & $74(34.3)$ \\
\hline & Moderate & $50(34.5)$ & $180(42.7)$ & $97(47.1)$ & $83(38.4)$ \\
\hline & A little serious & $11(7.6)$ & $45(10.7)$ & $25(12.1)$ & $20(9.3)$ \\
\hline & Never serious & $1(0.7)$ & $15(3.6)$ & $6(2.9)$ & $9(4.2)$ \\
\hline & Other & - & $7(1.7)$ & $3(1.5)$ & $4(1.9)$ \\
\hline \multirow[t]{8}{*}{ Violence type } & Teasing & $24(16.6)$ & $55(13.0)$ & $36(17.5)$ & $19(8.8)$ \\
\hline & Light violence & $7(4.8)$ & $37(8.8)$ & $28(13.6)$ & $9(4.2)$ \\
\hline & Bullying & $36(24.8)$ & $120(28.4)$ & $54(26.2)$ & 66 (30.6) \\
\hline & Ripoff & $28(12.4)$ & $51(12.1)$ & $26(12.6)$ & $25(11.6)$ \\
\hline & Sexual violence & $6(4.1)$ & $43(10.2)$ & $16(7.8)$ & $27(12.5)$ \\
\hline & Verbal, psychological violence & $23(15.9)$ & $54(12.8)$ & $18(8.7)$ & $36(16.7)$ \\
\hline & Collective violence requiring medical treatment & $15(10.3)$ & $42(10.0)$ & $20(9.7)$ & $22(10.2)$ \\
\hline & Other & $16(11.0)$ & $20(4.7)$ & $8(3.9)$ & $12(5.6)$ \\
\hline \multirow[t]{8}{*}{ Reasons for Violence } & Without any reason & $64(44.1)$ & $188(44.8)$ & $91(44.4)$ & $97(45.1)$ \\
\hline & To steal money & $33(22.8)$ & $85(20.2)$ & $41(20.0)$ & $44(20.5)$ \\
\hline & Due to a promise & $2(1.4)$ & $2(0.5)$ & $1(0.5)$ & $1(0.5)$ \\
\hline & Just because of looking at the offenders & $5(3.4)$ & $30(7.1)$ & $15(7.3)$ & $15(7.0)$ \\
\hline & Due to speaking carelessly & $20(13.8)$ & $62(14.8)$ & $38(18.5)$ & $24(11.2)$ \\
\hline & Because of not saying hello & - & - & - & - \\
\hline & Due to smiling & - & $10(2.4)$ & $7(3.4)$ & $3(1.4)$ \\
\hline & Other & $21(14.5)$ & $43(10.2)$ & $12(5.9)$ & $31(14.4)$ \\
\hline \multirow[t]{5}{*}{ Characteristics of the offenders } & Seniors of the same school & $18(12.6)$ & $72(17.3)$ & $18(8.8)$ & $54(25.4)$ \\
\hline & Classmates & $106(74.1)$ & $285(68.3)$ & $168(82.4)$ & $117(54.9)$ \\
\hline & Seniors of another school & $2(1.4)$ & $34(8.2)$ & $6(2.9)$ & $28(13.1)$ \\
\hline & The same-grade students of another school & $3(2.1)$ & $6(1.4)$ & $3(1.5)$ & $3(1.4)$ \\
\hline & Other & $14(9.8)$ & $20(4.8)$ & $9(4.4)$ & $11(5.2)$ \\
\hline \multirow[t]{7}{*}{ The subject of help requests } & Teachers of the school & $40(28.4)$ & $95(22.7)$ & $49(24.0)$ & $46(21.4)$ \\
\hline & Parents, Family & $42(29.8)$ & $179(42.7)$ & $73(35.8)$ & $106(49.3)$ \\
\hline & Education office & $1(0.7)$ & $6(1.4)$ & $4(2.0)$ & $2(0.9)$ \\
\hline & Police officers & - & $47(11.2)$ & $33(16.2)$ & $14(6.5)$ \\
\hline & Friends, seniors, juniors & $35(24.8)$ & $56(13.4)$ & $26(12.7)$ & $30(14.0)$ \\
\hline & Will not say to anybody & $16(11.3)$ & $21(5.0)$ & $12(5.9)$ & $9(4.2)$ \\
\hline & Other & $7(5.0)$ & $15(3.6)$ & $7(3.4)$ & $8(3.7)$ \\
\hline \multirow{2}{*}{ Whether or not victims asked for help } & Yes & 86 (59.7) & $65(15.5)$ & $35(17.0)$ & $30(14.0)$ \\
\hline & No & 58 (40.3) & 355 (84.5) & $171(83.0)$ & 184 (86.0) \\
\hline
\end{tabular}

(continued to the next page)

make the most efforts for removing school violence. The results are presented in Table 3.

\section{Perceptions of the students and teachers on the reasons for school violence and the necessary eradication measures}

Regarding the reasons for the persistence of school violence, the test statistics and mean values of the differences between the reasons perceived by teachers and by students are shown in Table 4 .

In order to identify the differences between male and female stu- dents, a test of the difference was conducted, the results of which are presented in Table 5 .

\section{The most urgent measures needed for eradicating the school violence.}

The differences in the mean values for the teachers and students regarding the most urgent measures required for eradicating school violence were tested, the results of which are shown in Table 6. 
Table 3. continued

\begin{tabular}{|c|c|c|c|c|c|}
\hline \multirow{2}{*}{ Variables } & \multirow{2}{*}{ Classification } & \multirow{2}{*}{ Teacher (n, \%) } & \multicolumn{3}{|c|}{ Students (n, \%) } \\
\hline & & & Total & Male & Female \\
\hline \multirow[t]{7}{*}{ The reason for not asking for help } & Thinking that it would be of no use to tell & $19(14.4)$ & $73(17.8)$ & $45(22.5)$ & $28(13.3)$ \\
\hline & Fear of the offender's reprisals & $93(70.5)$ & $234(56.9)$ & $104(52.0)$ & $130(61.6)$ \\
\hline & Trying to resolve it by oneself & $3(2.3)$ & $15(3.6)$ & $10(5.0)$ & $5(2.4)$ \\
\hline & Thinking that it has nothing to do with him or her & $9(6.8)$ & $39(9.5)$ & $20(10.0)$ & $19(9.0)$ \\
\hline & Feeling troublesome and shameful & $1(0.8)$ & $20(4.9)$ & $11(5.5)$ & $9(4.3)$ \\
\hline & Because of loyalty to the offenders & $2(1.5)$ & $6(1.5)$ & $4(2.0)$ & $2(0.9)$ \\
\hline & Other & $5(3.8)$ & $24(5.8)$ & $6(3.0)$ & $18(8.5)$ \\
\hline \multirow[t]{6}{*}{ Degree of help obtained upon asking } & Never helpful & $1(0.7)$ & $26(6.2)$ & $9(4.5)$ & $17(7.9)$ \\
\hline & Not very helpful & $16(11.1)$ & $90(21.5)$ & $49(24.3)$ & $47(19.0)$ \\
\hline & Moderate & $43(29.9)$ & $126(30.1)$ & $51(25.2)$ & $75(34.7)$ \\
\hline & A little bit helpful & $70(48.6)$ & $84(20.1)$ & 40 (19.8) & $44(20.4)$ \\
\hline & Very helpful & $14(9.7)$ & $39(9.3)$ & $27(13.4)$ & $12(5.6)$ \\
\hline & Other & - & $53(12.7)$ & $26(12.9)$ & $27(12.5)$ \\
\hline \multirow{8}{*}{$\begin{array}{l}\text { The institutes that should strive to } \\
\text { prevent the school violence }\end{array}$} & Home & $97(67.4)$ & $66(15.8)$ & $22(10.8)$ & $44(20.5)$ \\
\hline & School & $25(17.4)$ & $203(48.6)$ & $99(48.8)$ & $104(48.4)$ \\
\hline & The police & $2(1.4)$ & $43(10.3)$ & $31(15.3)$ & $12(5.6)$ \\
\hline & Community organizations & - & $4(1.0)$ & $4(2.0)$ & - \\
\hline & Residents & - & $7(1.7)$ & $3(1.5)$ & $4(1.9)$ \\
\hline & Child protection organizations & $1(0.7)$ & $60(14.4)$ & $35(15.8)$ & $28(13.0)$ \\
\hline & Education office & - & $10(2.4)$ & $8(3.9)$ & $2(0.9)$ \\
\hline & Others & $19(13.2)$ & $25(6.0)$ & $4(2.0)$ & $21(9.8)$ \\
\hline
\end{tabular}

*Violence prevention institution was allowed multiple responses $(\mathrm{n}=712)$.

Table 4. Differences between teachers and students in the perceived reasons for the persistence of school

\begin{tabular}{|c|c|c|c|c|c|c|c|c|}
\hline \multirow{2}{*}{ Variables } & \multirow{2}{*}{ Classification } & \multicolumn{3}{|c|}{ Teachers (n) } & \multicolumn{3}{|c|}{ Students (n) } & \multirow{2}{*}{ F-test } \\
\hline & & $\mathrm{n}$ & M & SD & $n$ & M & SD & \\
\hline \multirow{7}{*}{$\begin{array}{l}\text { Reasons for the persistence } \\
\text { of school violence }\end{array}$} & Lack of interests from teachers and parents & 141 & 3.23 & 1.09 & 408 & 3.03 & 1.18 & $95.72^{* * *}$ \\
\hline & Focus of education system on entrance-exams & 143 & 3.64 & 0.94 & 406 & 2.89 & 1.18 & $65.21^{* * *}$ \\
\hline & Lack of cultural facilities and leisure activities for the students & 143 & 3.85 & 0.8 & 408 & 2.87 & 1.21 & $138.27^{* *}$ \\
\hline & Lack of professional school counselors & 143 & 3.31 & 0.85 & 409 & 2.67 & 1.13 & $104.74^{* * *}$ \\
\hline & Harmful environments around the school & 143 & 3.83 & 0.71 & 408 & 3.13 & 1.17 & $58.61^{* * *}$ \\
\hline & Home environmental impacts (Remarriage, divorce) & 142 & 4.55 & 0.6 & 408 & 3.17 & 1.25 & $315.16^{* * *}$ \\
\hline & Influences of peers, culture and the media & 143 & 4.28 & 0.65 & 409 & 3.34 & 1.16 & $115.30^{* * *}$ \\
\hline
\end{tabular}

Table 5. Tests on gender differences in student perception of the reasons for the persistence of school violence

\begin{tabular}{|c|c|c|c|c|c|c|c|c|}
\hline \multirow{3}{*}{ Variables } & \multirow{3}{*}{ Classification } & \multicolumn{6}{|c|}{ Students } & \multirow{3}{*}{ t-test } \\
\hline & & \multicolumn{3}{|c|}{ Male } & \multicolumn{3}{|c|}{ Female } & \\
\hline & & $\mathrm{n}$ & M & SD & n & M & SD & \\
\hline \multirow{7}{*}{$\begin{array}{l}\text { Reasons for the persistence of } \\
\text { school violence }\end{array}$} & Lack of interest from teachers and parents & 196 & 2.97 & 1.24 & 212 & 3.09 & 1.11 & -1.07 \\
\hline & Focus of education system on entrance-exams & 194 & 2.75 & 1.2 & 212 & 3.02 & 1.15 & $-2.29^{*}$ \\
\hline & Lack of cultural facilities and leisure activities for the students & 196 & 2.98 & 1.27 & 212 & 2.77 & 1.15 & 1.72 \\
\hline & Lack of professional school counselors & 197 & 2.64 & 1.17 & 212 & 2.71 & 1.09 & -0.61 \\
\hline & Harmful environments around the school & 196 & 3.09 & 1.26 & 212 & 3.16 & 1.09 & -0.59 \\
\hline & Home environmental impacts (Remarriage, divorce) & 196 & 2.82 & 1.29 & 212 & 3.5 & 0.12 & $-5.76^{* *}$ \\
\hline & Influences of peers, culture and the media & 196 & 3.14 & 1.29 & 213 & 3.52 & 1 & $-3.33^{* *}$ \\
\hline
\end{tabular}


Table 6. Differences in the perceived most urgent measures for eradicating school violence

\begin{tabular}{|c|c|c|c|c|c|c|c|c|}
\hline \multirow{2}{*}{ Variables } & \multirow{2}{*}{ Classification } & \multicolumn{3}{|c|}{ Teachers (n) } & \multicolumn{3}{|c|}{ Students (n) } & \multirow{2}{*}{ F-test } \\
\hline & & $n$ & M & SD & $n$ & M & SD & \\
\hline \multirow[t]{10}{*}{$\begin{array}{l}\text { The most urgent measures } \\
\text { for eradicating school violence }\end{array}$} & $\begin{array}{l}\text { Frequent consultation with the students by counseling } \\
\text { teachers }\end{array}$ & 144 & 3.72 & 0.7 & 391 & 3.23 & 1.06 & $56.09^{* * *}$ \\
\hline & Conducting regular surveys on school violence & 145 & 3.39 & 0.78 & 390 & 3.24 & 1.06 & $9.81^{* *}$ \\
\hline & Installing victim-reporting boxes inside the school & 145 & 3.6 & 0.79 & 390 & 3.43 & 1.07 & 3.72 \\
\hline & Activating the student-counseling room & 145 & 3.83 & 0.79 & 389 & 3.37 & 1.1 & $30.22^{* * *}$ \\
\hline & Strengthening teacher patrol of the school & 145 & 3.62 & 0.76 & 390 & 3.52 & 1.11 & $15.27^{* * *}$ \\
\hline & Reforming the entrance exam-oriented education & 145 & 3.9 & 0.97 & 390 & 3.34 & 1.08 & $33.13^{* * *}$ \\
\hline & Clean up of the environments harmful to the students & 145 & 4.26 & 0.71 & 389 & 3.51 & 1.04 & $59.77^{* * *}$ \\
\hline & Supporting healthy group activities for the students & 145 & 3.98 & 0.75 & 389 & 3.4 & 1.02 & $60.93^{* * *}$ \\
\hline & Treating the offenders harshly & 145 & 4.24 & 0.77 & 389 & 3.96 & 1.08 & $33.58^{* * *}$ \\
\hline & $\begin{array}{l}\text { Developing programs for victim protection and offender } \\
\text { guidance }\end{array}$ & 145 & 4.29 & 0.75 & 390 & 3.56 & 1.09 & $79.44^{* * *}$ \\
\hline
\end{tabular}

\section{DISCUSSION}

Based on the results found in this study, in order for school violence prevention measures to have an effect, the following interventions should be considered.

First, for effective school violence prevention activities, the professionalism of the school staff who respond to the violence should be enhanced (Williams et al., 2004). The current measures against school violence are not effective due to the common structural problems of insufficient personnel and budgets, as well as insufficient professionalism of the school staff who deal with the violence.

Second, the current control-driven polices need to be stopped, and the effort needs to be switched to focus on prevention-oriented policies. To this end, the clean-up of harmful environments should be done in conjunction with civilian organizations, and ongoing preventive patrol and control is necessary around crime-ridden places with the high possibility of crime occurrence (Hunter, 2000). In addition, since the concerns of teenagers are shared between peers, peer-counseling leadership training programs, as a precaution, should be activated, and more active action programs such as field visiting activities should be created (Adler et al., 1993).

Third, ongoing violence prevention education and human rights education should be carried out. Human rights education should be provided for teenagers who are exposed to violence-related cultures, as well as for the students, teachers, and parents facing the repressive culture of entrance examination-oriented education (Shoemaker, 1984). Therefore, efforts to spread human rights education programs across the board are needed (Moon,
2006). While school-violence reaction measures and case-centric lectures have recently been made through crime prevention classrooms, institutional schemes to ensure more professional and practical education are needed with human-rights education counseling and violence-prevention curriculum (Becker et al., 1993).

Fourth, community networks need to be organized solidly (Bartol and Anne, 2008). The role of community networks is to ensure the operation of a comprehensive and systematic program within the community, with the established databases of school consultation results and police receipts, and the processing of school violence while building a 'School Violence Surveillance Network.' This can be accomplished by formulating networks among the associated entities based on cooperative links between homes, schools, education offices, and local governments. To do this, a professional organization which can manage school violence scientifically and systematically needs to be established (Borum, 2000).

Finally, since the biggest reason for difficulty reporting the occurrence of school violence was found to be fear of reprisal, appropriate protection for whistleblowers needs to be ensured. Measures of the alliance system to provide support for the victims to adapt to school and social life should be prepared, while motivating victim reporting through the strictly assurance of maintaining identity secrecy of the victim students and whistleblowers, as well as the designation of dedicated police-supporting systems for the continued protection of the victims and operation of a school-wide support system (Anderson, 1997).

This study examined the prevention activities and reaction measures regarding school violence. Overall, resolution of the 
problem of school violence should start with the efforts of society to identify the fundamental causes surrounding the violence, based on an understanding of the realities faced by the students. This should be followed by the persistent practices of education, focusing on prevention and guidance, while the joint efforts of entire societies are needed concurrently, with the leading roles of the home, schools, and communities, as well as institutional support of the government.

\section{CONFLICT OF INTEREST}

No potential conflict of interest relevant to this article was reported.

\section{ACKNOWLEDGMENTS}

This paper was supported by Hankuk University of Foreign Studies Research Fund of 2014.

\section{REFERENCES}

Adler P. Wheeling and dealing. Collumbia University Press 1993;21-30.
Anderson CA. Effects of violent movies and trait hostility on hostile feelings and aggressive thoughts. Aggress Behav 1997;23:161-178.

Bartol CR, Anne MB. Criminal behavior, upper saddle river, NJ: Pearson Education, Inc,. 2008;170-176.

Becker H. Outsider: Studies in the Sociology of Deviance, New York: Macmillian 1993.

Borum R. Assessing violence risk among youth. J Clin Psychol 2000;56:1018.

Conklin JE. Criminology, 4th ed., New York: Macmillian Publishing Company 1992.

Hunter RD. Thomas Baker Police-Community Relations the Administration of Justice, New Jersey: Prentice-Hall. Inc 2000;641-655.

Moon YR. School violence school prevention and consultation. Hakjisa 2006;11-88.

Shoemaker DJ. Theories of delinquency: An examination of explanations of delinquent behavior. New York: Oxford University Press 1984.

Siegel L, Cullen FT, Ball RA. Criminological theory: Context and consequences, Newbury Park: Sage Publications 1989.

Williams KS. Textbook on criminology, New York: Oxford University Press 2004.

Zillmann D. Cognition-excitation interdependence in aggressive behavior. Aggress Behav 1998;14:51-64. 